\title{
From Traumatic Childhood to Cocaine Abuse: The Critical Function of the Immune System
}

\author{
Luisa Lo lacono, Clarissa Catale, Alessandro Martini, Alessandro Valzania, \\ Maria Teresa Viscomi, Valerio Chiurchiù, Ezia Guatteo, Silvia Bussone, Fabiana Perrone, \\ Paola Di Sabato, Eleonora Aricò, Alberto D’Argenio, Alfonso Troisi, Nicola B. Mercuri, \\ Mauro Maccarrone, Stefano Puglisi-Allegra, Pietro Casella, and Valeria Carola
}

\begin{abstract}
BACKGROUND: Experiencing traumatic childhood is a risk factor for developing substance use disorder, but the mechanisms that underlie this relationship have not been determined. Adverse childhood experiences affect the immune system, and the immune system mediates the effects of psychostimulants. However, whether this system is involved in the etiology of substance use disorder in individuals who have experienced early life stress is unknown. METHODS: In this study, we performed a series of ex vivo and in vivo experiments in mice and humans to define the function of the immune system in the early life stress-induced susceptibility to the neurobehavioral effects of cocaine. RESULTS: We provide evidence that exposure to social stress at an early age permanently sensitizes the peripheral (splenocytes) and brain (microglia) immune responses to cocaine in mice. In the brain, microglial activation in the ventral tegmental area of social-stress mice was associated with functional alterations in dopaminergic neurotransmission, as measured by whole-cell voltage clamp recordings in dopamine neurons. Notably, preventing immune activation during the social-stress exposure reverted the effects of dopamine in the ventral tegmental area and the cocaine-induced behavioral phenotype to control levels. In humans, cocaine modulated toll-like receptor 4-mediated innate immunity, an effect that was enhanced in those addicted to cocaine who had experienced a difficult childhood.

CONCLUSIONS: Collectively, our findings demonstrate that sensitization to cocaine in early life-stressed individuals involves brain and peripheral immune responses and that this mechanism is shared between mice and humans.
\end{abstract}

Keywords: Childhood maltreatment, Cocaine, Dopamine, GW2580, Microglia, Minocycline, Stress, Toll-like receptor 4, Ventral tegmental area

https://doi.org/10.1016/j.biopsych.2018.05.022

A traumatic childhood is a risk factor for developing substance use disorder (1-4). Compared with individuals who have not experienced adverse childhood events, adults who have been subjected to severe childhood maltreatment (CM) are 7- to 10fold more likely to report addiction to illicit drugs (5). Childhood adversity negatively influences all stages of the addiction process, including the initiation of drug consumption, the transition to compulsive drug use, and the long-term maintenance of the addicted state $(5,6)$. Owing to the extent of this clinical phenomenon, the biological mechanisms that underlie this relationship must be identified.

Adverse childhood experiences can activate the innate immune system and trigger an inflammatory response in humans $(7,8)$. Because the development of the immune system is not completed at birth, instead continuing its maturation in response to postnatal environmental stimulation, it can be influenced significantly by exposure to psychosocial stress in childhood. This event can elicit permanent sensitization of the immune system, resulting in greater responses to psychosocial and immune challenges later in life (7).
Psychostimulants affect the immune system and alter the circulating levels of inflammatory cytokines, in turn inducing cognitive and behavioral changes in rodents (9). These drugs can function, in part, as proinflammatory stimuli and danger signals that induce the immune system to produce extreme neuroinflammatory responses (10). Interestingly, toll-like receptor 4 (TLR4), a key component of the innate immunity, has been recently shown to mediate the reinforcing and rewarding properties of psychostimulants, such as cocaine, in murine models $(11,12)$.

Based on this evidence, the link between traumatic childhood experiences and the susceptibility to substance use disorder, as mediated by the immune system, must be examined.

To test the hypothesis that a sensitized immune system renders $\mathrm{CM}$ individuals more susceptible to the effects of cocaine, several issues must be addressed: 1) Do CM individuals develop greater immune responses to cocaine in the periphery and brain? 2) What are the acute effects of early life stress experiences on the brain immune system? and 3) Are 
these effects responsible for the long-lasting susceptibility to cocaine?

Based on the largely recognized limitations of clinical research in answering these questions, we first performed a preclinical murine study and then conducted a human clinical study to preliminarily translate the mouse findings.

\section{METHODS AND MATERIALS}

\section{Mouse Study}

Animals and Stress Procedure. DBA/2J@Ico (Charles River Laboratories Italia, Calco, Italy) male and female mice were mated at 12 weeks of age. The social-stress (S-S) procedure was applied as previously described from postnatal day (PD) 14 to PD 22 (13) (Figure 1A; Supplement).

Pharmacological Treatments. Minocycline hydrochloride (M9511; Sigma-Aldrich, Milan, Italy) and GW2580 (S8042; Selleck Chemicals, Houston, TX) were used to inhibit microglial activation (more details can be found in the Supplement).

RNA Purification From Leukocyte or Total Brain. Blood and brains were collected from naïve adult control and S-S mice, and from S-S and control mice exposed to the long conditioned place preference (CPP) protocol (Figure 1A, Supplement). Procedures for collection, brain dissection, and RNA purification are detailed in the Supplement.

Gene Expression Microarray and Data Analysis. Microarray experiments on leukocyte RNA were performed as previously described (13) and are detailed in the Supplement.

\section{Quantitative Real-Time Reverse Transcriptase- Polymerase Chain Reaction and Gene Expression Analysis. Quantitative real-time reverse transcriptase- polymerase chain reaction was used to evaluate gene expression levels in total brain RNA samples of S-S and con- trol mice exposed to the long CPP protocol (Figure 1A) as well as leukocyte RNA samples of naïve adult S-S and control mice. The procedure is detailed in the Supplement.}

Splenocytes' Inflammatory Activation and Poly-
chromatic Flow Cytometry. Splenocyte isolation and stimulation, and analysis of cytokine productions, was performed according to Chiurchiù et al. (14) and is detailed in the Supplement.

Histological Procedures. Procedures for brain collection, slice preparation, and immunoreactions are detailed in the Supplement.

Electrophysiological Experiment. Cell-attached and whole-cell patch clamp recordings were conducted on single ventral tegmental area (VTA) dopamine (DA) neurons in midbrain slices according to published procedures $(15,16)$ at PD 22 (see Supplement).

CPP Protocol. Three-month-old mice were tested in the CPP protocol as previously described $(13,17)$ (see Supplement).

\section{Human Study}

Participants. The clinical sample referred to the Centers for Substance Abuse Treatment of Rome and Molise and consisted of 38 cocaine-addicted individuals having received a DSM-5 diagnosis of cocaine use disorder. The control group included 20 healthy volunteers with absence of current or past psychiatric disorders as confirmed by diagnostic interview (see Supplement and Supplemental Table S1).

\section{Human Plasma Collection and RNA Extraction From Leukocytes. Blood (15 mL) was drawn from all participants at the end of the clinical assessment. Procedures for collection of plasma, collection of leukocytes, and RNA purification are detailed in the Supplement.}

Measurement of Plasma Inflammatory Mediators. To allow the simultaneous detection and quantification of multiple targets on the same sample, Multiplex Bead-based Luminex Assay was performed to measure several cytokines (interleukin $[\mathrm{IL}]-1 \beta$, IL-6, tumor necrosis factor alpha [TNF- $\alpha], \mathrm{IL}-12)$ and other inflammatory mediators ( $\mathrm{C}-\mathrm{X}-\mathrm{C}$ motif chemokine ligand 10, intercellular adhesion molecule 1, matrix metallopeptidase 9) in the plasma obtained from participants. The multiplex assay was performed according to manufacturer instructions and read on a Luminex200 analyzer (Luminex Corp., Austin, TX).

Figure 1. Social stress (S-S) in early life alters inflammatory pathways in response to cocaine in adulthood. (A) S-S protocol applied from postnatal days 14 to 21 and conditioned place preference (CPP) protocol (long) used to measure cocaine-induced behavior, applied from postnatal days 90 to 120 . During S-S pups were exposed daily to an adult CD1 male mouse for 30 minutes. In the conditioning phase of the CPP, mice were treated with a 5 -mg/kg dose of cocaine. Blood for microarray analysis was collected 6 hours after the extinction test. (B) Microarray analysis of RNAs extracted from blood leukocytes of S-S and control (CTR) mice ( $n=8$ per group) at cocaine withdrawal showed that 847 annotated genes were differentially expressed between the groups. The Gene Ontology revealed a significant enrichment in PANTHER (Protein Analysis Through Evolutionary Relationships) inflammation mediated by chemokine and cytokine signaling pathway. Twenty-eight genes (marked in red) annotated to this PANTHER pathway were used as input for the functional association network creation. The other 50 genes here represented are related genes belonging to the same pathway: some of them (in gray) are not differentially expressed in our experiment, and others (in red) show significant modulations between CTR and S-S mice. In the pop-up histograms, the expression differences detected by the microarray (represented as log intensity values, indicative of messenger RNA abundance for any given gene) are provided for the following genes: Tollip, Ptpla, Pdgfa, and Itga2b. (C) These genes were differentially expressed between CTR and S-S mice also in the brain $\left(P t p l a ~\left[t_{11}=-2.81, p=.017\right], P d g f a\left[S t u d e n t t_{11}=\right.\right.$ 2.382, $p=.048$ ], Itga2 $b$ [Student $t_{11}=2.290, p=.049$ ], Tollip [Student $t_{11}=3.063, p=.009$ ]; $n=7$ per group). ${ }^{*} p<.05,{ }^{\star *} p<.01,{ }^{\star \star \star} p<.001$. RT-PCR, reverse transcriptase polymerase chain reaction. 
A

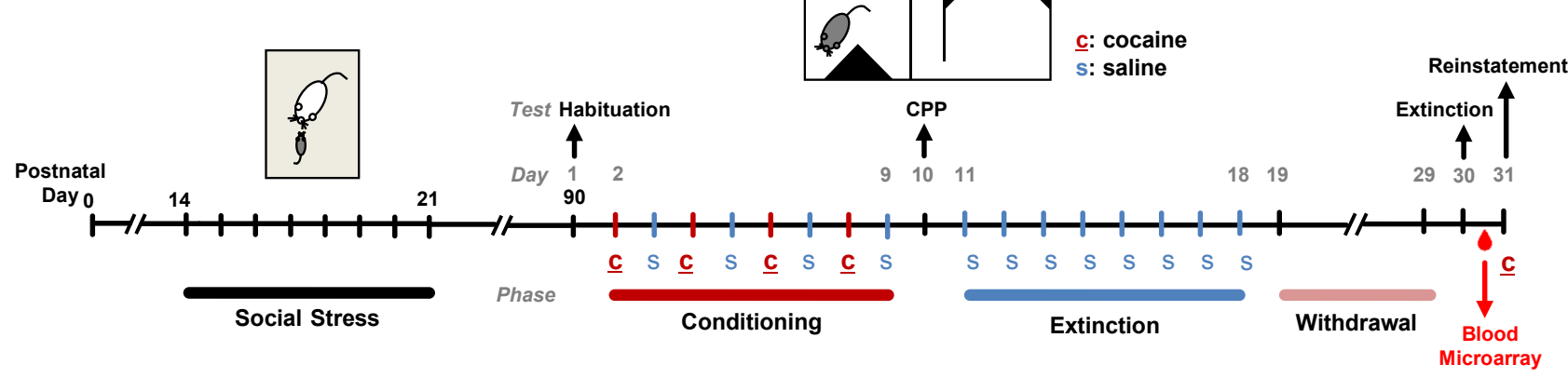

B

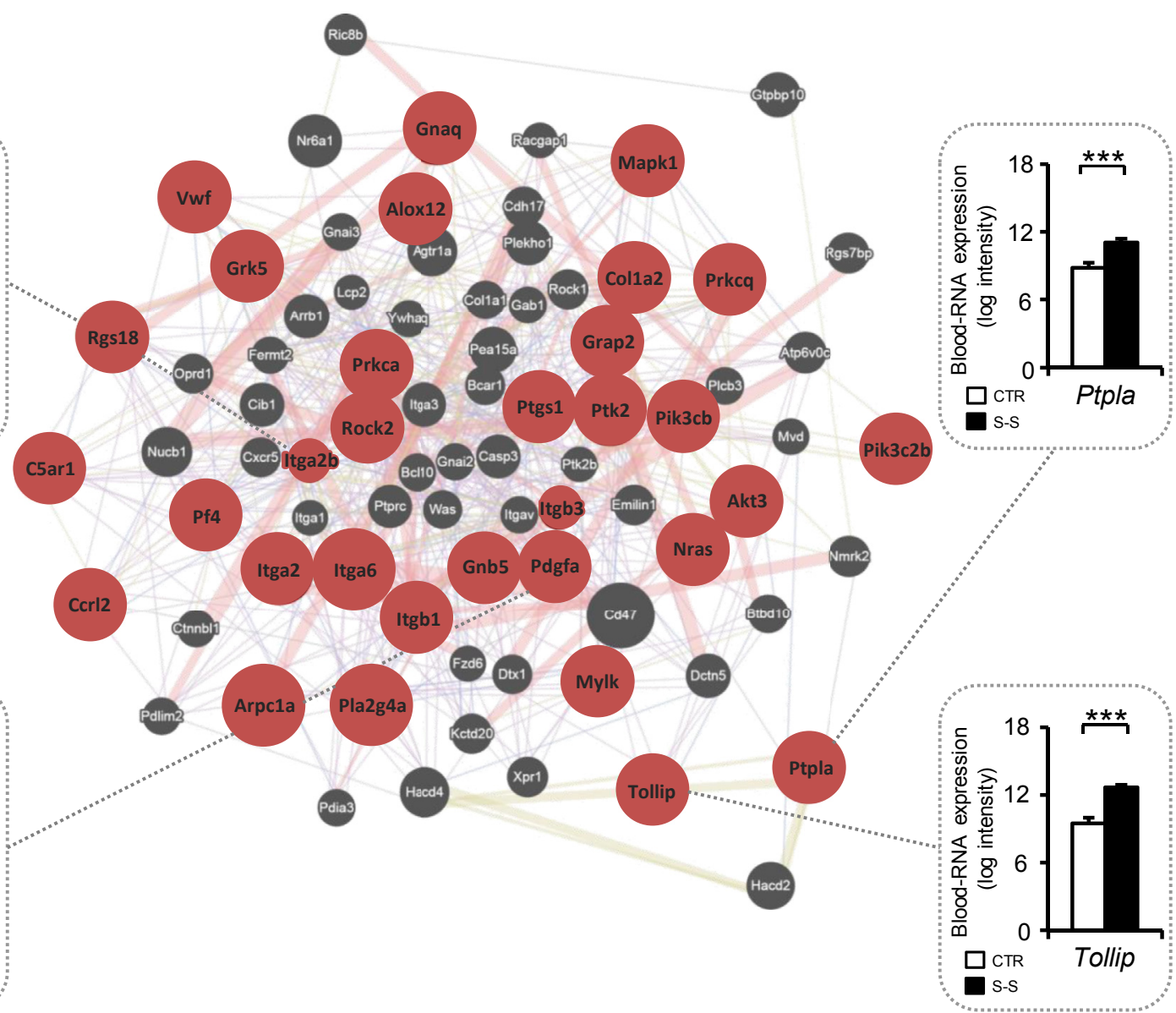

C

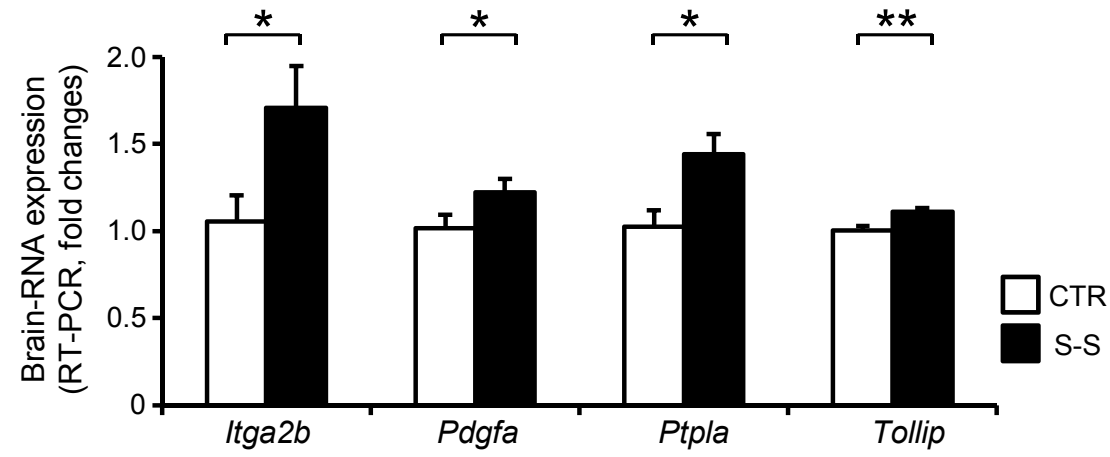


A
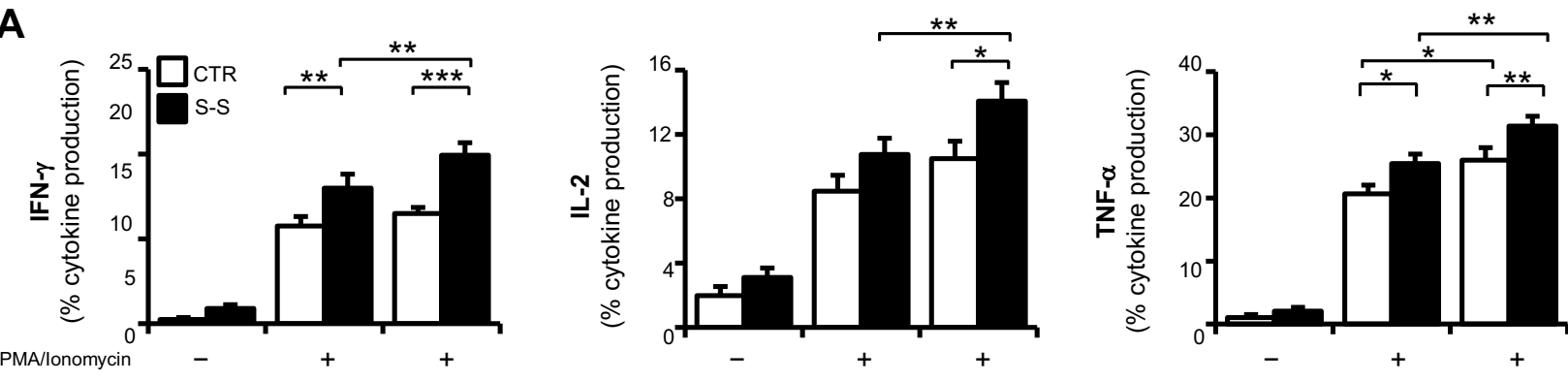

Cocaine $1 \mu \mathrm{M}$

\section{B}
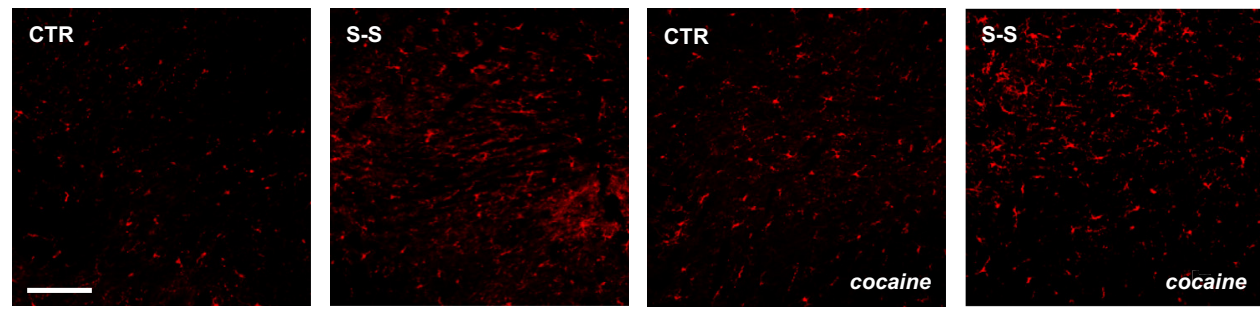

C

E

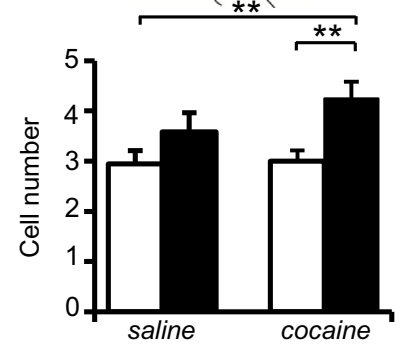

H

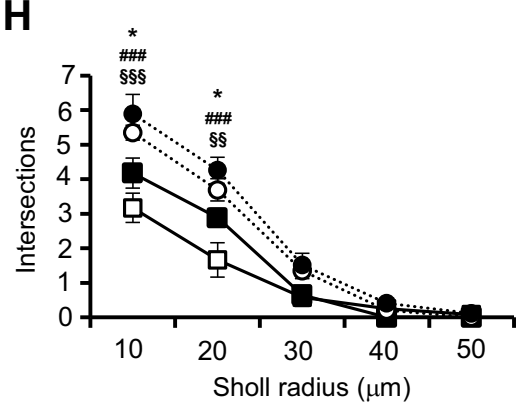

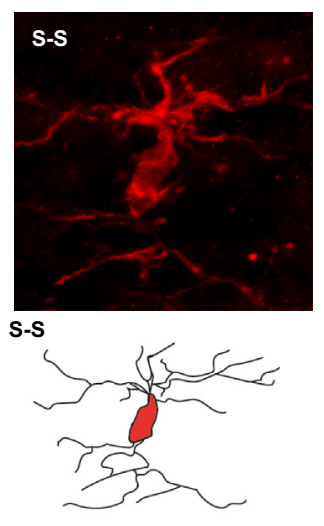

$\mathbf{F}$
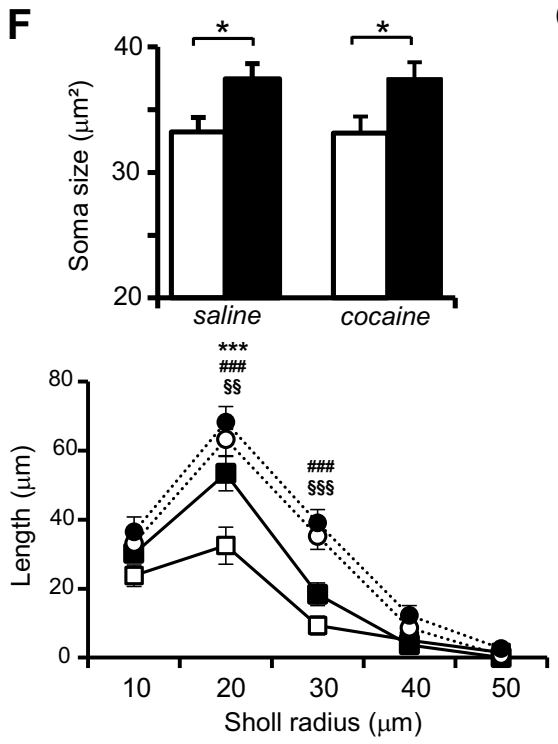

CTR

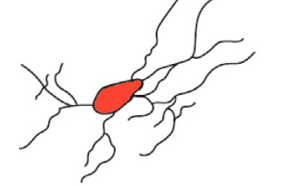

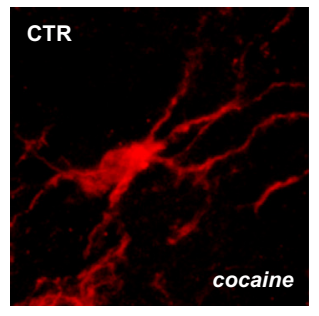

G
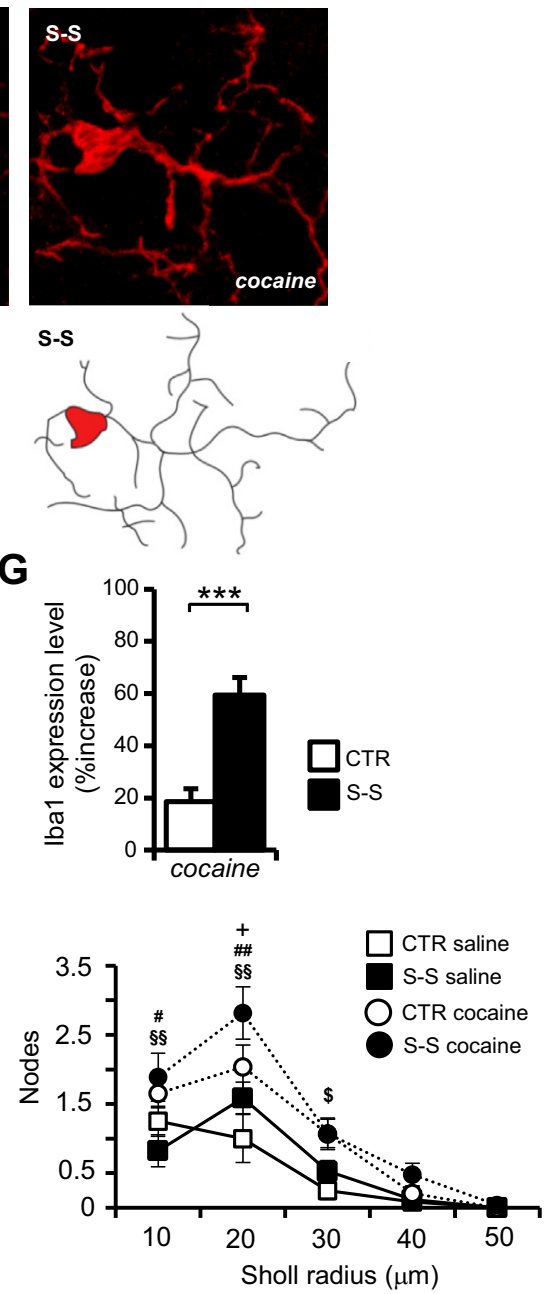


\section{Quantitative Real-Time Reverse Transcriptase Poly- merase Chain Reaction and Gene Expression Ana-} Iysis. Quantitative reverse transcriptase polymerase chain reaction was performed as described for the mouse study. TaqMan primer sets (Applied Biosystems, Waltham, MA) are provided in the Supplement.

Statistics. All data were checked for normal distribution, with measures failing Shapiro-Wilk's test analyzed by nonparametric procedures. All other parameters were subjected to parametric procedures. Details can be found in the Supplement.

\section{RESULTS}

\section{Mouse Study}

S-S in Early Life Alters Inflammatory Pathways in Response to Cocaine in Adulthood. By exposing mouse pups to a threatening adult male mouse (S-S), we increased the susceptibility to cocaine-induced effects (Figure 1A, Supplemental Figures S1 and S2) (13).

We have recently performed a transcriptome analysis of blood leukocytes from S-S and control mice exposed to the long CPP protocol (Figure 1A) (13). A detailed analysis of differentially expressed genes is described in the Supplement. PANTHER (Protein Analysis Through Evolutionary Relationships) pathway analysis confirmed a significant enrichment in genes that are involved in pathways such as the endothelin signaling pathway and the inflammatory response mediated by cytokines and chemokines (PANTHER pathway P00031) (Figure 1B, Supplemental Table S2). To get a sense of concordance between blood and brain gene expression modifications, we chose a sublist of 37 genes among the total number of differentially expressed genes, following inclusive criteria like higher statistical significance (smallest $p$ value) or participation in the significantly enriched pathways. We then compared their level of expression in total brain RNA extracts of S-S and control mice. Interestingly, seven of 37 genes were found differentially expressed also in the brain (Supplemental Table S3). Among these, four of seven genes, including protein-tyrosine phosphatase-like member A (Ptpla), plateletderived growth factor subunit A (Pdgfa), integrin subunit alpha $2 \mathrm{~b}$ (Itga2b), and toll interacting protein (Tollip) (Figure 1C), fall in the inflammatory response mediated by cytokines and chemokines pathway. Notably, most of the variations between control and S-S mice detected after cocaine exposure were not observed before cocaine exposure (Supplement and Supplemental Table S4).

We next examined whether S-S exposure modifies the peripheral immune system functioning in the long term. Thus, we analyzed the ex vivo inflammatory response of activated splenocytes from adult S-S and control mice to cocaine stimulation in terms of cytokine production. The number of activated cells that produced the proinflammatory cytokines interferon gamma $($ IFN $-\gamma$ ) and TNF- $\alpha$, and to a lesser extent IL-2, was higher when obtained from S-S mice compared with control mice, and this difference was amplified by the addition of cocaine to the medium at all different doses used (Figure 2A, Supplemental Figure S3). Although S-S cells produced significantly higher amounts of all cytokines upon stimulation with cocaine, this seemed to be particularly relevant for IFN- $\gamma$ and IL-2 inasmuch as cocaine alone did not significantly upregulate these two cytokines in control cells (Figure 2A, Supplemental Figure S3). Differences in cytokine production were not due to differences in leukocyte cell numbers (Supplemental Table S5).

We examined microglial activation in the VTA by means of ionized calcium-binding adapter molecule 1 positive $(\mathrm{lba} 1+)$ cells in S-S and control mice in adulthood after repeated saline or cocaine injections. We found that while the number of lba1+ microglial cells in the VTA between saline S-S and control adult mice was not altered, a significant increase of the lba1+ cell number was observed in S-S compared with control mice after cocaine exposure (Figure 2B, E). Moreover, cocaine produced

Figure 2. Social stress (S-S) in early life sensitizes the peripheral and central immune response to cocaine in adulthood. (A) Intracellular cytokine expression (interferon gamma [IFN- $\gamma$ ], interleukin [IL]-2, and tumor necrosis factor alpha [TNF- $\alpha$ ]; represented as percent of cytokine-producing cells) from total splenocytes of adult S-S and control (CTR) mice left untreated or stimulated with phorbol myristate acetate (PMA) (100 ng/mL)/ionomycin (1 $\mu \mathrm{M})$ for 6 hours in the presence or absence of cocaine $\left(1 \mu \mathrm{M}\right.$; two-way analysis of variance [ANOVA]: IFN- $\gamma$ group effect $\left[F_{1,30}=22.854, p<.001\right]$, IL-2 group effect $\left[F_{1,30}=9.377, p=\right.$ .005], TNF- $\alpha$ group effect $\left[F_{1,30}=11.404, p=.002\right] ; n=6$ per group). Data were acquired by flow cytometry. ${ }^{\star} p<.05,{ }^{\star *} p<.01,{ }^{\star \star \star} p<.001 .(\mathbf{B}-\mathbf{D})$ Morphological correlates of microglia in adult S-S and CTR mice before or after repeated cocaine injections, as revealed by ionized calcium-binding adapter molecule 1 (lba1) immunohistochemistry and confocal microscopy analysis. (E) The number of lba1-positive cells (labeled cells in a single squared box [200 $\mu \mathrm{m} \times 200 \mu \mathrm{m}]$ randomly positioned in five regularly spaced sections) was similar between adult CTR and S-S mice but was increased in S-S mice after repeated cocaine injections (daily dose of $5 \mathrm{mg} / \mathrm{kg}$ received four times on alternating days; ANOVA early environment effect $\left[F_{1,55}=10.562, p=.002\right] ; n=4$ per group). (F) On the contrary, the soma size of microglial cells was significantly increased in S-S mice compared with CTR before and after cocaine exposure (Kruskal-Wallis ANOVA [H $\left.\mathrm{H}_{3,263}=12.050, p=.007\right]$; CTR cells: $n=53$, S-S cells: $n=72$; CTR + cocaine cells: $n=69$, S-S + cocaine cells: $n=71$ ). (G) Iba1 expression levels (percent increase of lba1 cocaine-induced expression: this value was obtained by subtracting the immunofluorescence value, measured in mice after cocaine treatment, from the mean values assessed in mice of the same group exposed to saline) show a greater increase of Iba1 expression in S-S mice compared with CTR mice after cocaine exposure (Mann-Whitney test $[U=1760.50, p=.004]$ ). (H) Sholl analysis of microglial processes shows that the process length and number of intersections are significantly higher in adult S-S mice compared with CTR mice before cocaine exposure (repeated-measures ANOVA [RM-ANOVA] for intersections, early environment effect $\left[F_{1,81}=4.010, p=.048\right]$; RM-ANOVA for length, early environment effect $\left[F_{1,81}=4.819, p=\right.$ .031]; RM-ANOVA for length, early environment $\times$ distance/radius effect $\left[F_{4,324}=2.604, p=.036\right]$; CTR cells: $n=12, \mathrm{~S}-\mathrm{S}$ cells: $\left.n=17\right)$. Microglial process/ dendritic complexity was increased in both groups (CTR and S-S) after cocaine treatment (RM-ANOVA for intersections, treatment effect $\left[F_{1,81}=23.086, p<\right.$ $.001]$; RM-ANOVA for intersections, treatment $\times$ distance/radius effect $\left[F_{4,324}=7.552, p<.001\right]$; RM-ANOVA for length, treatment effect $\left[F_{1,81}=27.483, p \leq\right.$ .001]; RM-ANOVA for length, treatment $\times$ distance/radius effect $\left[F_{4,324}=10.640, p<.001\right]$; RM-ANOVA for nodes, treatment effect $\left.\left[F_{1,81}=15.784, p \leq .001\right]\right)$. After cocaine exposure the number of nodes at radius $20 \mu \mathrm{m}$ was significantly higher in S-S mice compared with CTR mice (RM-ANOVA for nodes, treatment effect $\times$ distance/radius effect $\left[F_{4,324}=3.710, p=.006\right]$; CTR + cocaine cells: $n=29$, S-S + cocaine cells: $\left.n=27\right)$. (B) Scale bar $=100 \mu \mathrm{m}$. (C) Scale bar $=10$ $\mu \mathrm{m}$. (E-G) ${ }^{\star} p<.05,{ }^{\star \star} p<.01,{ }^{\star \star \star} p<.001$. (H) CTR + saline vs. S-S + saline: ${ }^{\star} p<.05,{ }^{\star \star \star} p<.001$. CTR + cocaine vs. S-S + cocaine: $+p<.05$. CTR + saline

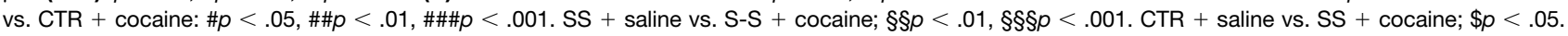




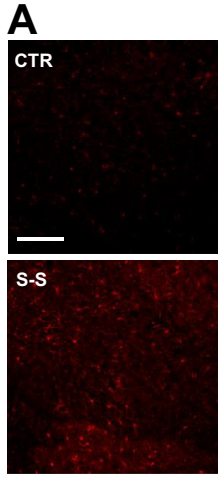

B
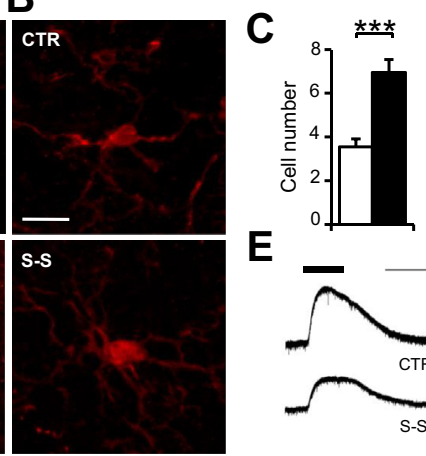

$\mathrm{E}$
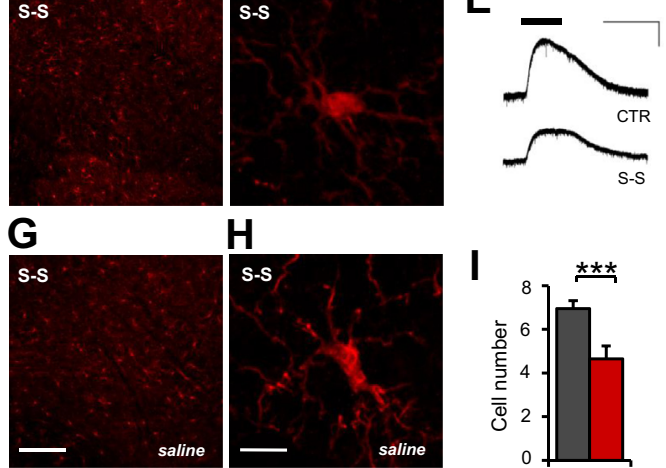

H
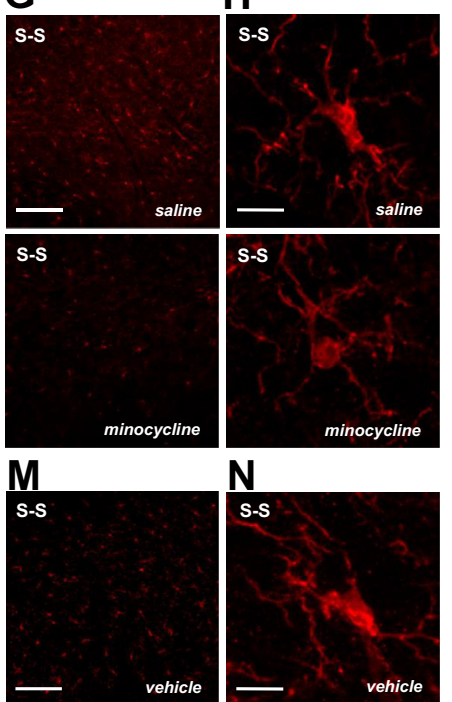

$\mathrm{N}$
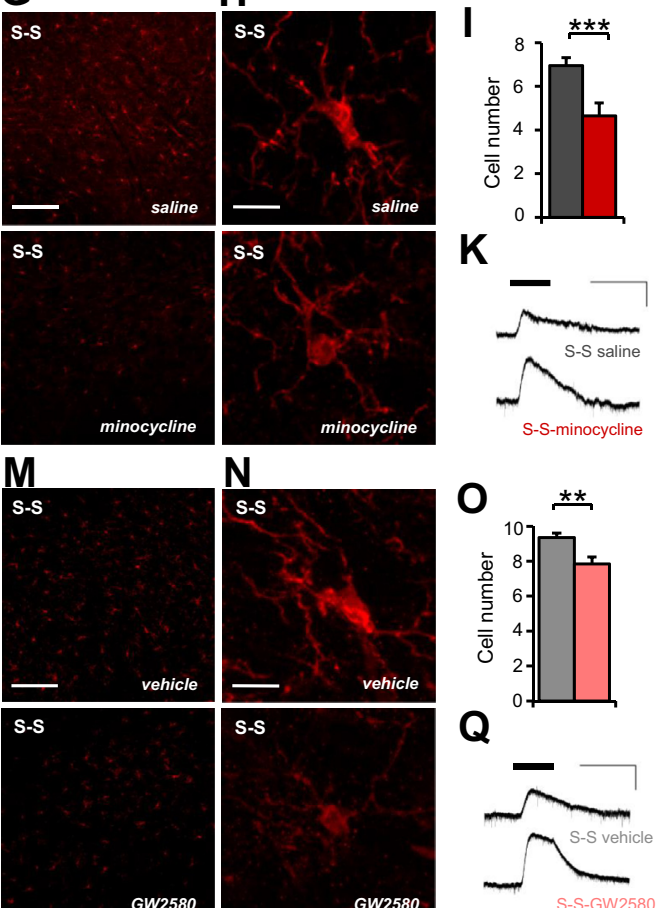

$\mathrm{K}$
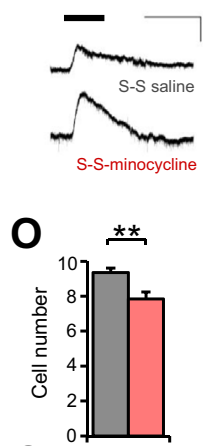

Q

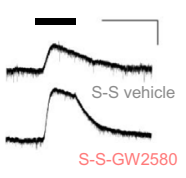

D

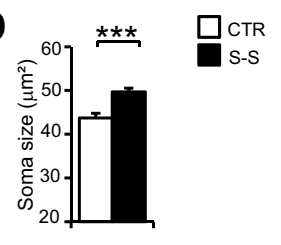

$\mathbf{F}$
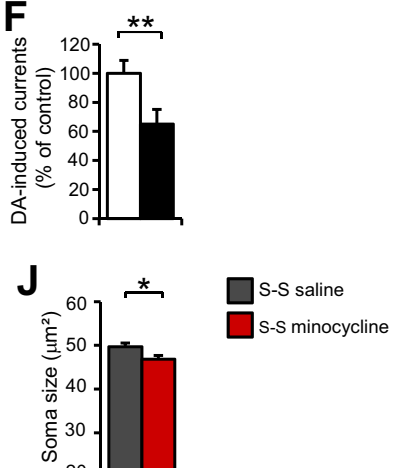

L

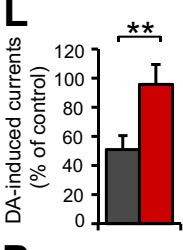

$\mathbf{P}$

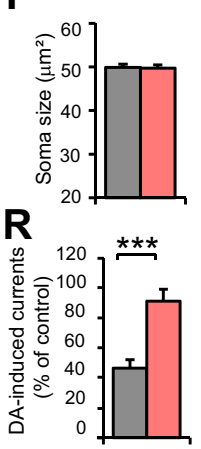

Figure 3. Social stress (S-S) causes microglial activation and reduces dopamine currents in the ventral tegmental area (VTA) after stress procedure. (A, B) Morphological correlates of microglial activation as revealed by ionized calcium-binding adapter molecule 1 (lba1) immunohistochemistry and confocal microscopy analysis. (C, D) The number of Iba1-positive cells (labeled cells in a single squared box [200 $\mu \mathrm{m} \times 200 \mu \mathrm{m}$ ] randomly positioned in five regularly spaced sections) and the soma size of microglial cells (control [CTR] cells: $n=75$, S-S cells: $n=157$ ) were significantly increased in S-S pups compared with CTR pups at the end of the stress exposure (at postnatal day [PD] 22), suggesting the presence of reactive microglia in the former group (number of cells $\left[t_{27}=-4.182, p<.001\right]$; soma size, Mann-Whitney test [ $U=4061, p<.001] ; n=4$ per group). (E) Representative traces of outward currents induced by bath application of dopamine (DA) (30 $\mu \mathrm{M}, 3$ minutes), recorded by means of whole-cell patch clamp recordings $\left(\mathrm{V}_{\mathrm{h}}=-60 \mathrm{mV}\right)$ from CTR and S-S VTA DA neurons, in midbrain slices (scale bar $=3$ minutes, $50 \mathrm{pA})$. (F) Mean values of DA-induced outward currents, expressed as percentage of control currents, show lower current amplitudes in S-S ( $n=11$ cells) compared with CTR neurons $\left(n=13\right.$ cells) at PD $22\left(t_{22}=-2.84, p=\right.$ .009). (G, H) Morphological correlates of microglial cells as revealed by lba1 immunohistochemistry and confocal microscopy analysis after minocycline treatment applied during the stress exposure. (I, J) The number of lba1-positive cells (labeled cells in a single squared box [200 $\mu \mathrm{m} \times 200 \mu \mathrm{m}$ ] randomly positioned in five regularly spaced sections) and the soma size of microglial cells were significantly decreased in S-S pups treated with minocycline compared with S-S pups exposed to saline $(n=4$ per group), suggesting that the minocycline treatment counteracted the microglial activation induced by $S-S$ (number of cells after minocycline $\left[t_{33}=\right.$ 3.336, $p=.002$ ]; soma size, Mann-Whitney test $[U=$ 8471, $p<.0486$ ]; S-S + saline cells: $n=157$; S-S + minocycline cells: $n=125)$. (K) Representative traces of DA-outward currents $(30 \mu \mathrm{M}, 3$ minutes; $V_{\mathrm{h}}=-60 \mathrm{mV}$ ) recorded from S-S + saline and S-S + minocycline VTA DA neurons, in midbrain slices (scale bar $=3$ minutes, $50 \mathrm{pA}$ ). (L) Mean values of DA-induced outward currents, expressed as percentage of control currents, show that treatment of $S-S$ mice with minocycline rescues DA-current amplitudes of VTA neurons, in comparison with neurons of $S-S+$ saline mice (minocycline $\left[t_{25}=2.76, p=.010\right]$; S-S + saline cells: $n=15$, S-S + minocycline cells: $n=12$ ) at PD 22. (M, N) Morphological correlates of microglial cells as revealed by Iba1 immunohistochemistry and confocal microscopy analysis after GW2580 treatment applied during the stress exposure. (0) The number of lba1-positive cells (labeled cells in a single squared box [200 $\mu \mathrm{m} \times 200 \mu \mathrm{m}$ length] randomly positioned in five regularly spaced sections; GW2580 [ $\left.\left.t_{35}=2.858, p=.007\right]\right)$, (P) but not the soma size of microglial cells (S-S + vehicle cells: $n=208$, S-S + GW2580 cells: $n=264$ ), was significantly decreased in S-S pups treated with GW2580 compared with S-S pups exposed to the vehicle ( $n=4$ per group), suggesting that the GW2580 treatment counteracted the microglial activation induced by S-S. (Q) Example traces of DA-outward currents $\left(30 \mu \mathrm{M}, 3\right.$ minutes; $\left.\mathrm{V}_{\mathrm{h}}=-60 \mathrm{mV}\right)$ recorded from S-S + vehicle and S-S + GW2580 VTA DA neurons in midbrain slices (scale bar $=3$ minutes, $35 \mathrm{pA}$ ). (R) Mean values of DA-induced outward currents, expressed as percentage of control currents, show that treatment of S-S mice with GW2580 rescues DA-current amplitudes of VTA neurons, in comparison with neurons of S-S + vehicle mice (GW2580 $\left[t_{31}=-4.172, p<.001\right]$; S-S + vehicle cells: $n=14, \mathrm{~S}-\mathrm{S}+\mathrm{GW} 2580$ cells: $\left.n=19\right)$ at PD 22. (A, G, M) Scale bars $=100 \mu \mathrm{m}$. (B, H, N) Scale bar $=10 \mu \mathrm{m}$. ${ }^{\star} p<.05,{ }^{\star \star} p<.01,{ }^{\star \star *} p<.001$.

a higher percent increase in Iba1 expression level in S-S mice compared with control mice (Figure 2G).

On the contrary, the morphology of microglial cells in S-S mice was already altered under the saline condition, as shown by the significantly enlarged soma (Figure 2C, F) and altered ramification (Figure 2D). Specifically, by means of Sholl analysis we observed that the number of processes (intersections) and branch length were significantly higher in saline S-S mice compared with control mice at $20 \mu \mathrm{m}$ (radius $20 \mu \mathrm{m}$ ) from the cell soma, whereas these processes were almost completely absent at 30, 40, and $50 \mu \mathrm{m}$ from the cell soma (Sholl radii from 30 to $50 \mu \mathrm{m}$ ) in S-S group, suggesting a shrinkage of branches in this group (Figure 2D, H). Notably, while an effect of cocaine was not observed on soma size in both groups (Figure 2C, F), 
the microglial process/dendritic complexity was instead increased in both groups after treatment (Figure 2H). This complexity was even higher in S-S mice, with a significantly increased number of nodes at $20 \mu \mathrm{m}$ from the cell soma in this group compared with control mice after cocaine exposure (Figure 2H).

S-S Causes Microglial Activation and Reduces DA Currents in the VTA in Early Life. We then assessed whether the inflammatory changes observed in adult S-S microglia were a remnant of an acute inflammatory event that was induced by the stress experience in early life. We analyzed the VTA microglial population immediately at the end of the S-S (PD 22) and noted a change in the number and soma size of Iba1 + cells (Figure 3A-D). In contrast, microglial process length and ramification degree were unaffected in S-S mice. Microglia changes were not observed in other brain structures as nucleus accumbens and hippocampus (Supplemental Figure S4).

Based on the central role of the VTA in providing DA inputs to most regions of the brain (18-20), we examined the effects of the microglial activation observed at the end of the S-S on cell excitability of individual DA neurons. Within the VTA, DA neurons are autoinhibited by local DA release from their dendrites and axon collaterals by activating a $\mathrm{G}$ protein-gated inward-rectifier potassium channel 2-mediated (21-24) hyperpolarizing membrane current.

We examined whether the degree of self-inhibition of lateral VTA DA neurons was altered in S-S mice $(25,26)$. Using wholecell voltage clamp recordings, performed at the end of the stress procedure (PD 22), we measured the amplitude of the outward current that developed in response to exogenous DA application to individual DA neurons in midbrain slices. We observed lower amplitudes of DA-induced outward currents in VTA neurons of S-S mice compared with control mice (Figure 3E, F). No statistically significant difference was observed in membrane resistance (control mice: $350.71 \pm 65.7$ $\mathrm{M} \Omega$; S-S mice: $274.18 \pm 29.6 \mathrm{M} \Omega$ ) and $I_{\mathrm{h}}$ current at $-120 \mathrm{mV}$ (control mice: $-162.57 \pm 29.7$; S-S mice: $-115.83 \pm 19.2$ ) between S-S and control mice.

To determine whether the reduction of DA-induced outward currents in S-S DA neurons was due to changes in $D_{2}$ autoreceptor function, we used the selective $D_{2}$ agonist quinpirole instead of DA. We found that quinpirole-induced currents were similar in S-S and control neurons (Supplemental Figure S5), and the outward currents elicited by baclofen, the selective agonist of gamma-aminobutyric acid type B receptors also coupled to G protein-gated inward-rectifier potassium channel 2 channels (23), were not altered.

Pharmacological Prevention of Microglial Activation
During S-S Exposure Restores DA Neurons' Func-
tional Alteration. To demonstrate the relationship between
microglial activation and the functional impairments in DA
neurons in S-S mice, we prevented the immune system acti-
vation by exposing S-S or control pups to systemic adminis-
tration of minocycline (saline) and GW2580 (vehicle) during the
S-S treatment. Notably, in S-S mice both treatments, in addi-
tion to decreasing the number of Iba1+ cells (Figure 3I, O),
restored the neuronal sensitivity to DA, wherein the DA-
induced outward current in VTA DA neurons returned to control amplitudes (Figure 3K, L, Q, R). Interestingly, minocycline but not GW2580 produced a reduction in the soma size of Iba1 + cells (Figure 3J, P). In control mice, neither drug affected the DA-induced outward current despite a significant reduction in Iba1 + cells that was observed after GW2580 administration (Supplemental Figures S6 and S7).

Pharmacological Prevention of Microglial Activation During S-S, but Not in Adulthood, Prevents the Cocaine-Induced Behavioral Effects. We tested whether the major contribution to the increased susceptibility to cocaine observed in adult S-S mice $(13,27)$ would be rendered by the early consequences of immune activation in young age or by immune activation in adulthood.

Minocycline treatment during S-S (Figure 4A) restored normal behavior in the CPP protocol in adulthood, as S-S minocycline-treated mice no longer preferred the cocainepaired compartment (Figure 4B). The same treatment did not produce effect in the CPP protocol in control mice (Supplemental Figure S8).

In a second experiment, in adult mice, we applied a CPP protocol (Figure 4C) in which we inactivated microglia during cocaine conditioning by the systemic administration of GW2580. This treatment did not affect the preference for the cocaine-paired compartment, as both S-S and control GW2580-treated mice significantly preferred the cocainepaired compartment (Figure 4D).

\section{Human Study}

Increased Levels of Inflammatory Markers in Cocaine-Abstinent Individuals Exposed to Adverse Early Life Experiences. To explore the possibility that a sensitized immune system is associated with the experience of childhood adversity in individuals with cocaine addiction, we recruited a population of individuals who received a diagnosis of cocaine use disorder who were currently abstinent and under psychotherapeutic treatment. We performed a psychometric evaluation of the exposure to childhood and/or adolescent maltreatment and measured in blood leukocytes the transcriptional expression of genes that are mediators of innate immunity via the TLR4 signaling, including genes that were found to be significantly modulated in S-S mice during withdrawal (Figure 1B), like TOLLIP and IL-1 receptor accessory protein (which interacts with toll interacting protein to mediate the synthesis of proinflammatory factors, IL1RAP). The control and clinical samples did not differ for age or gender ratio. In the cocaineaddicted individuals, CM and no-CM groups did not differ in age of first cocaine exposure, lifetime cocaine abuse, and abstinence from cocaine (Supplemental Table S1).

We observed significantly higher messenger RNA expression levels of these three genes in cocaine-addicted individuals compared with control subjects (Figure 5A-C), suggesting that chronic cocaine use has persistent inflammatory effects. However, when the cocaine-dependent population was categorized by level of exposure to CM, these differences were driven primarily by the group that reported exposure to severe maltreatment at an early age (CM-cocaine) (Figure 5A-C). 


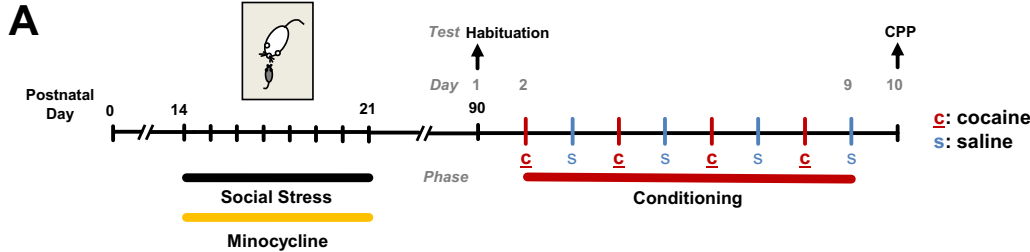

B
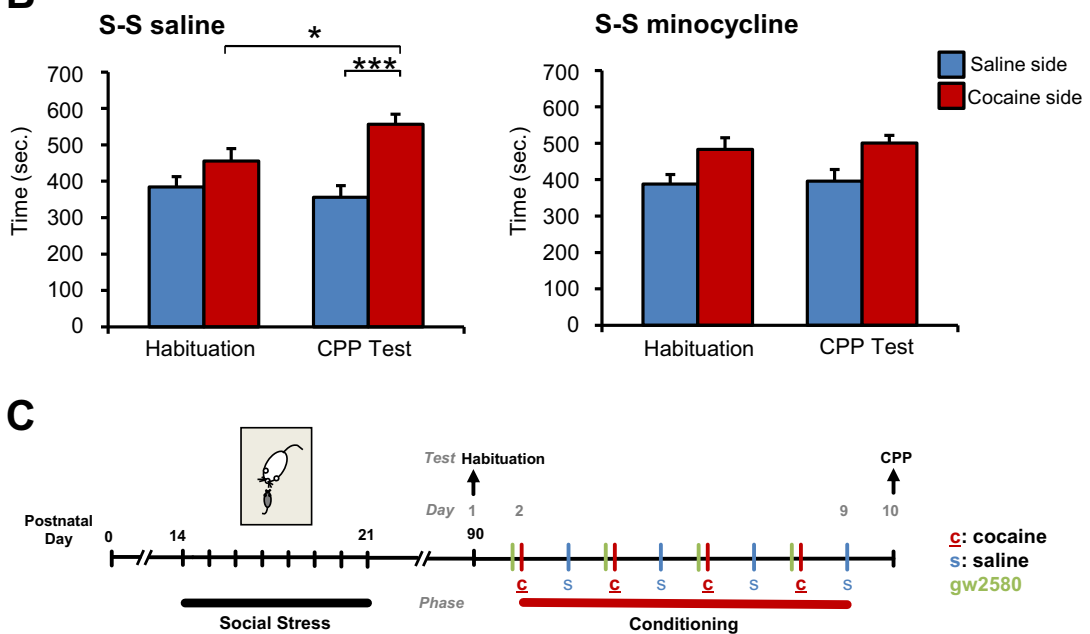

D CTR GW2580
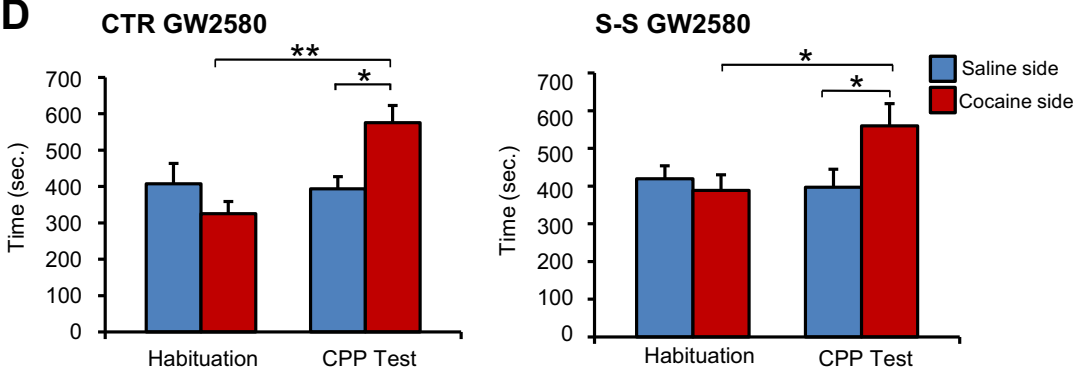

Figure 4. (A) Conditioned place preference (CPP) protocol used to test the effect of minocycline administration during social-stress (S-S) exposure on cocaine-induced behavior in adulthood. (B) Adult $\mathrm{S}$-S mice did not show preference for the cocainepaired compartment $(5 \mathrm{mg} / \mathrm{kg})$ at the CPP protocol when exposed to minocycline treatment during the S-S exposure (repeated-measures analysis of variance in S-S, time effect $\left[F_{3,15}=7.242, p=.003\right]$; $n=8$ per group). (C) CPP protocol used to test the effect of GW2580 administration in adult S-S and control (CTR) mice on cocaine-induced behavior. (D) GW2580 administration during cocaine conditioning did not affect the preference for the cocainepaired compartment, as both S-S and CTR GW2580-treated mice significantly preferred the cocaine-paired compartment, as was expected (repeated-measures analysis of variance, time effect $\left[F_{3,36}=7.772, p=.001\right] ; n=7$ per group). ${ }^{*} p<.05$, ${ }^{\star \star} p<.01,{ }^{\star \star \star} p<.001$.
The significant contribution of the CM-cocaine group to the difference in immune system regulation between control subjects and cocaine-addicted individuals was confirmed, based on the plasma protein levels of downstream TLR4-regulated inflammatory mediators, including IL-1 $\beta$, IL-6, TNF- $\alpha$, IL-12p70, and intercellular adhesion molecule 1. Consistently, the plasma levels of these factors were significantly greater in cocaine-addicted individuals compared with control subjects, and these levels were the highest in the CM-cocaine group (Figure 5D-H).

\section{DISCUSSION}

The link between an adverse childhood and the susceptibility to substance use disorder has been widely described. In this study, we have shown that the immune system mediates this relationship in mice and humans. In our preclinical mouse model $(13,27)$, we demonstrated that exposure to psychosocial stress in early life makes permanent changes in the peripheral and central immune system, rendering it more sensitive to immune challenges later in life. Splenocytes from adult S-S mice develop more extensive responses with regard to cytokine production to phorbol myristate acetate (Sigma-Aldrich, St. Louis, MO) alone or in combination with cocaine in adulthood.

Chronic psychosocial stress alters the secretion of proinflammatory cytokines, such as TNF- $\alpha$ and IL-6, by in vitro lipopolysaccharide-stimulated splenocytes $(28,29)$. Notably, in a recent human study, lymphocytes from adolescents with a history of maltreatment were shown to produce significantly more IL-2, IL-4, IFN- $\gamma$, and IL-17 following in vitro stimulation (30). These data are consistent and strengthen the model that early life stress affects the development of the immune system, sensitizing it to challenges later in life and thus predisposing individuals to inflammatory disease (7). Here, we tested the ability of cocaine to potentiate phorbol myristate acetateinduced immune stimulation in vitro. The effects of cocaine stimulation on cytokine production are often controversial, as both proinflammatory (31-33) and immunosuppressive (34) activities have been reported, likely owing to the disparate 

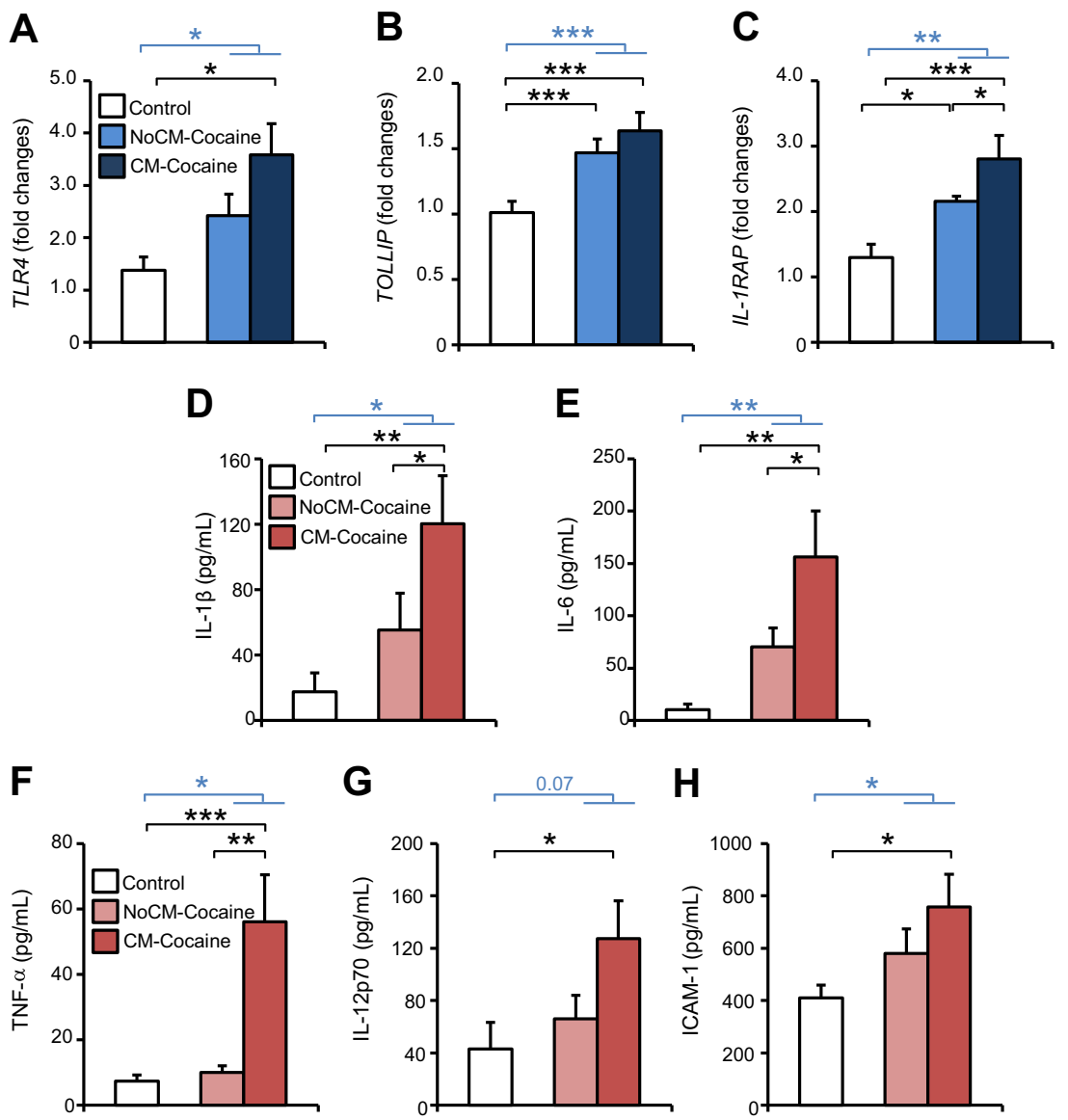

Figure 5. Increased levels of peripheral inflammatory markers in cocaine-abstinent individuals exposed to adverse early life stress experiences. (A-C) Blood leukocyte messenger RNA expression level of the toll-like receptor 4 (TLR4), its inhibitory protein toll interacting protein (TOLLIP), and interleukin (IL)-1 receptor accessory protein (IL1RAP) genes were upregulated in cocaine-addicted subjects compared with control subjects (blue lines and asterisks) (TLR4 [ $\left.t_{57}=2.198, p=.032\right]$, TOLLIP $\left[t_{57}=4.021, p=.001\right], I L 1 R A P\left[t_{57}=4.074, p=\right.$ .001]). Furthermore, in the cocaine-addicted group, the individuals with history of childhood maltreatment (CM-cocaine) $(n=17)$ showed a higher expression level of the investigated messenger RNAs compared with cocaine-addicted subjects without childhood trauma (NoCM-cocaine) ( $n=19)$, and control subjects $(n=24$; one-way analysis of variance: TLR4 $\left[F_{2,53}=3.368, p=.042\right]$, TOLLIP $\left[F_{2,53}=14.387, p=.001\right], \operatorname{IL} 1 R A P\left[F_{2,53}=10.626\right.$, $p=.001])$. (D-H) A number of plasma inflammatory mediators (including IL-1 $\beta$, IL-6, tumor necrosis factor alpha [TNF- $\alpha], \quad \mathrm{LL}-12 \mathrm{p} 70$, and intercellular adhesion molecule 1 [ICAM-1]) regulated by TLR4 (in $\mathrm{pg} / \mathrm{mL}$ ) were significantly higher in cocaineaddicted subjects compared with control subjects (blue lines and asterisks) (IL-1 $\beta\left[t_{31}=-2.435\right.$, $p=.021]$, IL-6 [ $\left.t_{31}=-2.881, p=.007\right]$, TNF- $\alpha$ $\left[t_{31}=-2.068, p=.047\right], \mathrm{IL}-12 \mathrm{p} 70\left[t_{31}=-1.844\right.$, $p=.074]$, ICAM-1 [ $\left.t_{31}=-2.207, p=.035\right]$ ), and again it was the individuals in the $\mathrm{CM}$-cocaine group who showed the highest levels of these markers among the experimental groups $(n=11$ per group; one-way analysis of variance: IL-1 $\beta\left[F_{2,30}=5.362\right.$, $p=.010]$, IL-6 $\left[F_{2,30}=7.126, p=.003\right]$, TNF- $\alpha$ $\left[F_{2,30}=10.555, p=.001\right]$, IL-12p70 $\left[F_{2,30}=3.677\right.$, $p=.037]$, ICAM-1 $\left.\left[F_{2,30}=3.357, p=.048\right]\right) .{ }^{*} p<.05$, ${ }^{\star \star} p<.01,{ }^{\star \star \star} p<.001$. experimental conditions. In our experiment, cocaine effected TNF- $\alpha$ secretion only in control mice, whereas the release of all cytokines rose in S-S mice, demonstrating greater sensitivity of these cells to cocaine. This peripheral alteration represents an important foundation for the translation of our results to clinical research, but the possibility that the observed immune sensitization to a cocaine stimulus enhances the susceptibility of our mice to the neurobehavioral effects of cocaine must be examined in the brain.

We analyzed the VTA, an area of the midbrain that supplies DA-releasing projections throughout the forebrain, which participates in the modulation of reward processes and in drug seeking, and is sensitive to stressors $(18,35)$.

In the brain, the immune system is primarily composed of microglial cells-highly dynamic and metamorphic cells that can undergo changes in shape, structure, and gene expression pattern according to their age, the brain structure in which they reside, and the state of activation induced by immune stimuli $(36,37)$.

In the VTA, the microglial morphological alterations in adult naïve S-S mice consist of soma enlargement, increased process complexity, and shrinkage of branches - all of which are consistent with a cell primed state (38). In the primed state, microglia are not inflammatory per se, but rather produce an exaggerated inflammatory response if stimulated (39). In our study, while a general effect of subchronic cocaine on the microglia ramification degree was observed in both groups of mice, corroborating previous findings in mice and humans (40-42), the increased lba1 expression, and the greater number of nodes close to the soma observed in the S-S compared with control VTA microglia may suggest a sensitization to the cocaine stimulus. However, this possibility needs further investigation.

Stressful events have recently been shown to affect microglia and induce priming (43). The two-hit hypothesis (44) proposes that early life stress primes microglial cells to respond in an inflated way to a subsequent challenge later in life, increasing the risk of developing a mental illness (43). Our findings show that exposure to S-S in early life induces lasting peripheral and brain inflammatory changes that may alter response to future immune challenges.

Thus, we hypothesize that the S-S experienced by the pups acts as an immune activator (first episode of immune activation) that permanently changes the microglia morphology. We have demonstrated that S-S is the factor that can induce an inflammatory episode in the VTA. This result expands on previous findings of long-term proinflammatory effects of early life psychological stress in other areas of the brain $(45,46)$.

Because the mesocorticolimbic DA system, of which the VTA is the key component, transits through a critical maturation phase-i.e., maturation of projections to the forebrain 
(47)-during the periadolescent age, we assume that the immune activation by S-S locally may interfere with this maturation and alters DA neuronal transmission, as observed in whole-cell voltage clamp experiments. In particular, the reduction in amplitude of DA-induced outward currents in the VTA suggests that $S-S$ reduces the degree of DA-mediated self-inhibition of VTA DA neurons. The responses of DA neurons to DA released in the ventral mesencephalon result from a complex interplay among $D_{2}$ autoreceptors, dopamine transporters, and the DA-degrading enzymes monoamine oxidase and catechol-O-methyltransferase $(25,48-50)$. Of note, we demonstrated, using quinpirole and baclofen, that the functions of $D_{2}$ autoreceptor and $G$ protein-gated inward-rectifier potassium channel 2 channels are not altered in S-S mice. Therefore, other mechanisms targeted by microglia in S-S mice might hamper the inhibition of the DA cells caused by DA (51). Thus, impaired autoinhibition may lead to increased DA neuron excitability and augmented DA release in target areas, a recently proposed risk factor for impulsive behavior, hyperactivity, drug addiction, and vulnerability to relapse (52).

The pharmacological experiments in which we administered minocycline or GW2580 during S-S demonstrated that the alterations in DA neurons in the VTA of S-S mice are mediated by immune system activation. Minocycline is a tetracycline antibiotic that is used to prevent microglial and macrophage activation (53), and in our experiment it maintained microglia in a resting state after S-S. However, the mechanism of action of minocycline lacks specificity; for example, it may affect the gut microbiome, which could partially contribute to the behavioral alterations (54). Thus, we replicate the experiment by using GW2580, a compound that inhibits colony-stimulating factor 1 signaling through specific inhibition of the cFMS kinase (55). Notably, GW2580 is known to target specifically stimulusinduced microglia and macrophage proliferation, but unlike direct inhibitors of the colony-stimulating factor 1 receptor, it does not produce microglial ablation (55). Nevertheless, in our hands it produced a reduction in lba1+ cells also in control mice, likely owing to the young age of microglial targeted cells. The contribution of brain microglial activation to DA transmission in cocaine abuse has been postulated-inflammatory cytokines that are secreted by activated microglia decrease DA synthesis and release through a variety of mechanisms $(51,56)$. However, developmentally, the mechanisms by which early stress-activated microglia affect DA neuron function must be examined further. Moreover, given that the systemic administration of minocycline or GW2580 affects also macrophage response in periphery, our experiment cannot rule out a contribution of the peripheral immune system.

According to the minocycline experiment, we have identified an interesting link: early life stress leads to microglial activation, which induces sensitization to the behavioral effects of cocaine. Indeed, by blocking S-S-induced microglial activation by minocycline, adult S-S mice lose their behavioral susceptibility to cocaine-induced effects. On the contrary, the blockade of microglial activity in adulthood by GW2580 did not prevent the sensitization to the behavioral effects of cocaine.

We uncovered a critical role of the immune system activation during early life in modulating the behavioral effects of cocaine, likely by altering the functionality in the dopaminergic neurotransmission in the VTA. On the other hand, microglial alterations in adulthood do not seem to be directly responsible for the behavioral effects of cocaine. In previous studies we have shown that a low dose of aspirin administered during cocaine withdrawal was sufficient to prevent the reinstatement of cocaine-induced CPP in S-S mice, suggesting that other mechanisms such as blood clotting and brain vasculature may contribute to the increased susceptibility of these mice to the behavioral effects of cocaine (13).

In the clinical study, we found that chronic cocaine use altered the expression of TLR4-mediated innate immunity, which was further modulated in the presence of CM. Cocaine alters the peripheral production of inflammatory mediators in humans (9,57-59). These findings corroborate and expand earlier data on altered immune system in individuals who experience CM (7), demonstrating that an early life stress experience permanently changes the responsiveness of the peripheral immune system to a substance of abuse, such as cocaine.

Our findings confirm that the sensitization to cocaine in early life-stressed individuals involves brain and peripheral immune responses and that this mechanism is shared between mice and humans. Our preclinical studies also demonstrate that the increased immune response alters VTA DA function and the behavioral effects of cocaine in mice, and implicates early life stress-induced immune modulation of the DA system in the brain as an etiological mechanism of cocaine addiction. An extensive longitudinal clinical study should be performed to verify whether this alteration is functional in humans.

\section{ACKNOWLEDGMENTS AND DISCLOSURES}

This work was supported by Italian Ministry of Health Young Researcher Grant No. GR-2009-1576820 (to VC), "2014-5 x mille" and "2015-6 x mille" grants (to VC), and University of Naples "Parthenope" Ricerca Locale 2017 (quote A) Grant No. D.P.R. 445/2000 (to EG).

We thank Professor Simona Cabib for her comments about the manuscript.

The authors report no biomedical financial interests or potential conflicts of interest.

\section{ARTICLE INFORMATION}

From the Institute for Research and Health Care, Santa Lucia Foundation (LLI, AM, AV, MTV, VC, EG, PDS, NBM, MM, SP-A, VC); Department of Psychology (LLI, CC, SB, SP-A), "Daniel Bovet" Center (LLI, CC, SB, SP-A), Ph.D. Program in Behavioral Neuroscience (CC), and Department of Biology and Biotechnologies (FP), University of Rome "La Sapienza"; Department of Systems Medicine (AM, AT, NBM), University of Rome Tor Vergata; Department of Medicine (VC, MM), Campus Bio-Medico University of Rome; Cell Factory FaBioCell (EA), Core Facilities, Istituto Superiore di Sanità; U.O.C. Psichiatria (AD), Policlinico Tor Vergata; and U.O.C. Dipendenze (PC), ASL ROMA1, Rome; and the Department of Motor Sciences and Wellness (EG), University of Naples "Parthenope," Naples, Italy.

$\mathrm{CC}$ and $\mathrm{AM}$ contributed equally to this work.

Address correspondence to Valeria Carola, Ph.D., Institute for Research and Health Care, Santa Lucia Foundation, Via del Fosso di Fiorano 64, 00143 Rome, Italy; E-mail: valeria.carola@uniroma1.it.

Received Nov 29, 2017; revised May 28, 2018; accepted May 29, 2018.

Supplementary material cited in this article is available online at https:// doi.org/10.1016/j.biopsych.2018.05.022.

\section{REFERENCES}

1. Elton A, Smitherman S, Young J, Kilts CD (2015): Effects of childhood maltreatment on the neural correlates of stress- and drug cue-induced cocaine craving. Addict Biol 20:820-831. 
2. Felitti VJ (2003): [Origins of addictive behavior: Evidence from a study of stressful chilhood experiences]. Prax Kinderpsychol Kinderpsychiatr 52:547-559.

3. Khoury L, Tang YL, Bradley B, Cubells JF, Ressler KJ (2010): Substance use, childhood traumatic experience, and Posttraumatic Stress Disorder in an urban civilian population. Depress Anxiety 27:10771086.

4. Van Dam NT, Rando K, Potenza MN, Tuit K, Sinha R (2014): Childhood maltreatment, altered limbic neurobiology, and substance use relapse severity via trauma-specific reductions in limbic gray matter volume. JAMA Psychiatry 71:917-925.

5. Dube SR, Felitti VJ, Dong M, Chapman DP, Giles WH, Anda RF (2003): Childhood abuse, neglect, and household dysfunction and the risk of illicit drug use: The adverse childhood experiences study. Pediatrics 111:564-572.

6. Enoch MA (2011): The role of early life stress as a predictor for alcohol and drug dependence. Psychopharmacology (Berl) 214:17-31.

7. Danese A, S JL (2017): Psychoneuroimmunology of early-life stress: The hidden wounds of childhood trauma? Neuropsychopharmacology 42:99-114.

8. Steptoe A, Hamer M, Chida Y (2007): The effects of acute psychological stress on circulating inflammatory factors in humans: A review and meta-analysis. Brain Behav Immun 21:901-912.

9. Yamada K, Nabeshima T (2004): Pro- and anti-addictive neurotrophic factors and cytokines in psychostimulant addiction: Mini review. Ann N Y Acad Sci 1025:198-204.

10. Frank MG, Watkins LR, Maier SF (2011): Stress- and glucocorticoidinduced priming of neuroinflammatory responses: Potential mechanisms of stress-induced vulnerability to drugs of abuse. Brain Behav Immun 25(suppl 1):S21-S28.

11. Hutchinson MR, Northcutt AL, Hiranita $T$, Wang $X$, Lewis SS, Thomas J, et al. (2012): Opioid activation of toll-like receptor 4 contributes to drug reinforcement. J Neurosci 32:11187-11200.

12. Northcutt $A L$, Hutchinson MR, Wang $X$, Baratta MV, Hiranita $T$, Cochran TA, et al. (2015): DAT isn't all that: Cocaine reward and reinforcement require Toll-like receptor 4 signaling. Mol Psychiatry 20:1525-1537.

13. Lo lacono L, Valzania A, Visco-Comandini F, Arico E, Viscomi MT, Castiello L, et al. (2017): Social threat exposure in juvenile mice promotes cocaine-seeking by altering blood clotting and brain vasculature. Addict Biol 22:911-922.

14. Chiurchiù V, Leuti $A$, Dalli J, Jacobsson A, Battistini L, Maccarrone M, et al. (2016): Proresolving lipid mediators resolvin D1, resolvin D2, and maresin 1 are critical in modulating T cell responses. Sci Transl Med 8:353ra111.

15. Guatteo E, Fusco FR, Giacomini P, Bernardi G, Mercuri NB (2000): The weaver mutation reverses the function of dopamine and GABA in mouse dopaminergic neurons. J Neurosci 20:6013-6020.

16. Mercuri NB, Bonci A, Calabresi P, Stefani A, Bernardi G (1995): Properties of the hyperpolarization-activated cation current Ih in rat midbrain dopaminergic neurons. Eur J Neurosci 7:462-469.

17. Orsini C, Bonito-Oliva A, Conversi D, Cabib S (2008): Genetic liability increases propensity to prime-induced reinstatement of conditioned place preference in mice exposed to low cocaine. Psychopharmacology (Berl) 198:287-296.

18. Dahlstrom A, Fuxe K (1964): Localization of monoamines in the lower brain stem. Experientia 20:398-399.

19. Noori HR, Schottler J, Ercsey-Ravasz M, Cosa-Linan A, Varga M, Toroczkai Z, et al. (2017): A multiscale cerebral neurochemical connectome of the rat brain. PLoS Biol 15:e2002612.

20. Ungerstedt $U$ (1971): Stereotaxic mapping of the monoamine pathways in the rat brain. Acta Physiol Scand Suppl 367:1-48.

21. Bayer VE, Pickel VM (1990): Ultrastructural localization of tyrosine hydroxylase in the rat ventral tegmental area: Relationship between immunolabeling density and neuronal associations. J Neurosci 10:2996-3013.

22. Johnson SW, North RA (1992): Two types of neurone in the rat ventral tegmental area and their synaptic inputs. J Physiol 450:455-468.
23. Lacey MG, Mercuri NB, North RA (1988): On the potassium conductance increase activated by GABAB and dopamine D2 receptors in rat substantia nigra neurones. J Physiol 401:437-453.

24. Reyes S, Fu Y, Double K, Thompson L, Kirik D, Paxinos G, et al. (2012): GIRK2 expression in dopamine neurons of the substantia nigra and ventral tegmental area. J Comp Neurol 520:2591-2607.

25. Krashia P, Martini A, Nobili A, Aversa D, D'Amelio M, Berretta N, et al. (2017): On the properties of identified dopaminergic neurons in the mouse substantia nigra and ventral tegmental area. Eur $\mathrm{J}$ Neurosci 45:92-105.

26. Lammel S, Ion DI, Roeper J, Malenka RC (2011): Projection-specific modulation of dopamine neuron synapses by aversive and rewarding stimuli. Neuron 70:855-862.

27. Lo lacono L, Valzania A, Visco-Comandini F, Viscomi MT, Felsani A, Puglisi-Allegra S, et al. (2016): Regulation of nucleus accumbens transcript levels in mice by early-life social stress and cocaine. Neuropharmacology 103:183-194.

28. Avitsur R, Kavelaars A, Heijnen C, Sheridan JF (2005): Social stress and the regulation of tumor necrosis factor-alpha secretion. Brain Behav Immun 19:311-317.

29. Stark JL, Avitsur R, Hunzeker J, Padgett DA, Sheridan JF (2002): Interleukin-6 and the development of social disruption-induced glucocorticoid resistance. J Neuroimmunol 124:9-15.

30. do Prado CH, Grassi-Oliveira R, Daruy-Filho L, Wieck A, Bauer ME (2017): Evidence for immune activation and resistance to glucocorticoids following childhood maltreatment in adolescents without psychopathology. Neuropsychopharmacology 42:2272-2282.

31. Di Francesco P, Marini S, Pica F, Favalli C, Tubaro E, Garaci E (1992): In vivo cocaine administration influences lymphokine production and humoral immune response. Immunol Res 11:74-79.

32. Falchetti R, Di Francesco P, Lanzilli G, Gaziano R, Casalinuovo IA, Ravagnan G, et al. (1995): In vitro effects of cocaine on cytokine secretion induced in murine splenic CD4 + T cells by antigen-specific stimulation. Cell Immunol 164:57-64.

33. Wang Y, Huang DS, Watson RR (1994): In vivo and in vitro cocaine modulation on production of cytokines in C57BL/6 mice. Life Sci 54:401-411.

34. Kubera M, Filip M, Budziszewska B, Basta-Kaim A, Wydra K, Leskiewicz M, et al. (2008): Immunosuppression induced by a conditioned stimulus associated with cocaine self-administration. J Pharmacol Sci 107:361-369.

35. Holly EN, Miczek KA (2016): Ventral tegmental area dopamine revisited: Effects of acute and repeated stress. Psychopharmacology (Berl) 233:163-186

36. De Biase LM, Schuebel KE, Fusfeld ZH, Jair K, Hawes IA, Cimbro R, et al. (2017): Local cues establish and maintain region-specific phenotypes of basal ganglia microglia. Neuron 95:341-356.e6.

37. Lynch MA (2009): The multifaceted profile of activated microglia. Mol Neurobiol 40:139-156.

38. Norden DM, Muccigrosso MM, Godbout JP (2015): Microglial priming and enhanced reactivity to secondary insult in aging, and traumatic CNS injury, and neurodegenerative disease. Neuropharmacology 96:29-41.

39. Perry VH, Holmes C (2014): Microglial priming in neurodegenerative disease. Nat Rev Neurol 10:217-224.

40. Lewitus GM, Konefal SC, Greenhalgh AD, Pribiag H, Augereau K, Stellwagen D (2016): Microglial TNF-alpha suppresses cocaineinduced plasticity and behavioral sensitization. Neuron 90:483-491.

41. Liao K, Guo M, Niu F, Yang L, Callen SE, Buch S (2016): Cocainemediated induction of microglial activation involves the ER stressTLR2 axis. J Neuroinflammation 13:33.

42. Little KY, Ramssen E, Welchko R, Volberg V, Roland CJ, Cassin B (2009): Decreased brain dopamine cell numbers in human cocaine users. Psychiatry Res 168:173-180.

43. Calcia MA, Bonsall DR, Bloomfield PS, Selvaraj S, Barichello T, Howes OD (2016): Stress and neuroinflammation: A systematic review of the effects of stress on microglia and the implications for mental illness. Psychopharmacology (Berl) 233:1637-1650. 
44. Hickie IB, Banati R, Stewart CH, Lloyd AR (2009): Are common childhood or adolescent infections risk factors for schizophrenia and other psychotic disorders? Med J Aust 190:S17-S21.

45. Dimatelis JJ, Pillay NS, Mutyaba AK, Russell VA, Daniels WM, Stein DJ (2012): Early maternal separation leads to down-regulation of cytokine gene expression. Metab Brain Dis 27:393-397.

46. Viviani B, Boraso M, Valero M, Gardoni F, Marco EM, Llorente R, et al. (2014): Early maternal deprivation immunologically primes hippocampal synapses by redistributing interleukin-1 receptor type I in a sex dependent manner. Brain Behav Immun 35:135-143.

47. Burke AR, Miczek KA (2014): Stress in adolescence and drugs of abuse in rodent models: Role of dopamine, CRF, and HPA axis. Psychopharmacology (Berl) 231:1557-1580.

48. Guldberg HC, Marsden CA (1975): Catechol-O-methyl transferase: Pharmacological aspects and physiological role. Pharmacol Rev 27:135-206.

49. Mercuri NB, Bonci A, Siniscalchi A, Stefani A, Calabresi P, Bernardi G (1996): Electrophysiological effects of monoamine oxidase inhibition on rat midbrain dopaminergic neurones: An in vitro study. $\mathrm{Br} \mathrm{J}$ Pharmacol 117:528-532.

50. Schmitz Y, Schmauss C, Sulzer D (2002): Altered dopamine release and uptake kinetics in mice lacking D2 receptors. J Neurosci 22:80028009.

51. Taylor AM, Castonguay A, Taylor AJ, Murphy NP, Ghogha A, Cook C, et al. (2015): Microglia disrupt mesolimbic reward circuitry in chronic pain. J Neurosci 35:8442-8450.

52. Bello EP, Mateo Y, Gelman DM, Noain D, Shin JH, Low MJ, et al. (2011): Cocaine supersensitivity and enhanced motivation for reward in mice lacking dopamine D2 autoreceptors. Nat Neurosci 14 1033-1038.

53. Kobayashi K, Imagama S, Ohgomori T, Hirano K, Uchimura K, Sakamoto K, et al. (2013): Minocycline selectively inhibits M1 polarization of microglia. Cell Death Dis 4:e525.

54. Kiraly DD, Walker DM, Calipari ES, Labonte B, Issler O, Pena CJ, et al. (2016): Alterations of the host microbiome affect behavioral responses to cocaine. Sci Rep 6:35455.

55. Olmos-Alonso A, Schetters ST, Sri S, Askew K, Mancuso R, VargasCaballero M, et al. (2016): Pharmacological targeting of CSF1R inhibits microglial proliferation and prevents the progression of Alzheimer'slike pathology. Brain 139:891-907.

56. Felger JC, Miller AH (2012): Cytokine effects on the basal ganglia and dopamine function: The subcortical source of inflammatory malaise. Front Neuroendocrinol 33:315-327.

57. Halpern JH, Sholar MB, Glowacki J, Mello NK, Mendelson JH, Siegel AJ (2003): Diminished interleukin-6 response to proinflammatory challenge in men and women after intravenous cocaine administration. J Clin Endocrinol Metab 88:1188-1193.

58. Irwin MR, Olmos L, Wang M, Valladares EM, Motivala SJ, Fong T, et al. (2007): Cocaine dependence and acute cocaine induce decreases of monocyte proinflammatory cytokine expression across the diurnal period: Autonomic mechanisms. J Pharmacol Exp Ther 320:507-515.

59. Fox HC, D'Sa C, Kimmerling A, Siedlarz KM, Tuit KL, Stowe R, et al. (2012): Immune system inflammation in cocaine dependent individuals: Implications for medications development. Hum Psychopharmacol 27:156-166. 